\title{
The Future Gap: Exploring a Critical Reflective Stakeholder Approach
}

\author{
Åsa Wikberg Nilsson (Corresponding author) \\ Department of Innovation and Design, Luleå University of Technology, Luleå 971 87, Sweden \\ Tel: 46-920-491342Ｅ-mail: asa.wikberg-nilsson@ltu.se \\ Ylva Fältholm \\ Department of Human Work Science, Luleå University of Technology, Luleå 971 87, Sweden \\ Tel: 46-920-491408Ｅ-mail: ylva.faltholm@ltu.se
}

Received: June 27, $2011 \quad$ Accepted: July 7, $2011 \quad$ doi:10.5539/jms.v1n1p18

The research is financed by AFA Insurance, FAS (Swedish Council of Working Life and Social Research), and the European Regional Development Fund

\begin{abstract}
The focus of this paper is a participatory design process that is used as a means to enable multiple stakeholders' collaboration in discussing strategies, designs and solutions of a conceptual future factory. The reason for this study is the Swedish industrial sector's difficulty in attracting women and young people. The design process can adapt to various complexities, building on the creative and innovative ability of collaborating people. In the present study, young people participated in explorations of images and perceptions of the current industrial sector and in an inquiry into the needs and preferences of a future factory. This activity resulted in two future scenarios: utopia, a positive future vision, and dystopia, a pessimistic outlook. These scenarios subsequently were used as means for critical reflection with multiple industrial sector stakeholders, exploring the future gap as the discrepancy between the images, perceptions and understanding held by internal stakeholders compared to external stakeholders. In this paper, we propose scenario-based design as one approach to multi-stakeholder activities, both for understanding various stakeholder needs and preferences and for critical reflection on future strategies and visions with a diversity of stakeholders. We believe there is a need for a transformation in the way in which organizations involve and connect to stakeholders.
\end{abstract}

Keywords: Multi-stakeholder approach, Participatory design, Corporate social responsibility, Future scenarios, Critical reflections

\section{Introduction}

This paper aims to explore a multiple-stakeholder approach to organisational development. This approach is used in a Participatory Design (PD) research project involving a diversity of stakeholders who participate in critical reflections on an entire industrial sector and, subsequently, in the design of a conceptual future factory. The motivation for this project is the difficulty that the Swedish manufacturing sector has faced in attracting women and young people as employees. The exploration of this problem was the point of departure for the interdisciplinary research project called 'the Future Factory'. In this project, a group of young people were invited to explore visions of the future; participants were asked questions such as what they would like the manufacturing sector to be like for them to consider it a future workplace. This study resulted in two future scenarios that subsequently were used as means to stimulate dialogue with industrial sector stakeholders. Therefore, in this paper, scenarios are explored as means for multi-stakeholder dialogue. The idea is that scenarios both can communicate various stakeholder needs and preferences and can be used for critical reflection on strategies, design and development in collaboration with multiple stakeholders. There is a lack of research addressing critical multi-stakeholder perspectives in relation to organizational design. Drawing from Miles et al.'s (2006) description of the 'the future gap' as the difference between the future visions held by corporate managers and those held by stakeholders, in this paper, we present an approach involving multiple stakeholders collaborating in workshop dialogues in order to minimize such gaps.

The Future Factory project approach draws inspiration from the field of design. In the last decade, a new design 
discipline has emerged, building on traditional design skills to address complex social and economic issues (The Design Council, 2006). In our study, the design process has been used as a means to enable multiple stakeholders to collaborate and discuss strategies, designs and solutions for a conceptual future factory. The design process can adapt to various circumstances and complexities, building on the creative and innovative ability of collaborating people. With this project, our aim is to create a good design, with systems, spaces, interactions and experiences that not only satisfy a function or solve a problem but also satisfy symbolic dimensions for multiple stakeholders. We propose that there is a need for a transformation in the way in which organizations involve and connect to stakeholders.

One obvious sign of the need for new forms of interactions with stakeholders is the aforementioned fact that the manufacturing sector does not attract young people, despite higher wages than are present in many other sectors. In Sweden, young people seem to value factors other than high wages, e.g., social networks and activities that provide authenticity and satisfaction (Ziebertz et al., 2005; Lindgren et al., 2005). There is an argument that young people are not attracted to the manufacturing sector because of a perception of an instrumental focus on standardization and discipline (Gillberg, 2010). Although we see this as an obvious reason for a conscious and pro-active multi-stakeholder strategy, this understanding of the sector may be one explanation for young people to opt out of industrial work. For this reason, in a design approach to future challenges, in the Future Factory project we have included both internal and external stakeholders in explorations of future scenarios of the Swedish manufacturing sector.

\subsection{The Future Factory Project}

'The Future Factory' is a three-year research project (2008-2010) performed by an interdisciplinary research team with expertise in the areas of production systems, systems design, gender, organizational design, ergonomics and industrial design. The reason for this project is the previously mentioned difficulty of the Swedish manufacturing sector in recruiting women and young people as employees. Despite gender mainstreaming efforts during the last decades, women still are in the minority within the Swedish manufacturing sector. Moreover, despite several campaigns to raise interest in industrial work and technology, young people still opt out of industrial work. For this reason, one way of increasing the sector's attractiveness may be to involve women and young people in dialogues regarding strategic planning, design and development of working environments and production systems. This pro-active approach is applied in the Future Factory project, which addresses the Swedish sector of manufacturing industry.

The practical aspect of the project is to explore the possibility of a collaborative design of an attractive, sustainable and efficient conceptual future factory. The project approach is based on the notion that organizational development must be continuously upgraded as the social context and conditions of production change. For that reason, our interest is in organizational workplace design and change management, i.e., how change is managed and who is involved in the process. For example, there is an argument for Swedish managers to advocate aspects such as meritocracy, autonomy and anti-hierarchical leadership (Isaksson, 2008). In the project, such positive aspects are explored, to reflect on the possible contribution of these aspects to a future factory where everyone who has a stake is allowed to participate on equal terms in meaningful dialogues on corporate strategies and activities. For the same reason, we have an interest in methods and concepts that support sustainable collaborative processes for change, with multiple stakeholders involved. The final phase of the project involves a team of women production engineers, systems designers, human resource managers, CEOs, industrial designers, architects, students and researchers in the design of the conceptual future factory (Wikberg Nilsson et al., 2010).

\section{The Concept of Stakeholders}

Stakeholder theory, originally proposed by Freeman (1984), is a common frame of reference when discussing stakeholder activities, both in organisations and academic writings. The concept is connected to a tradition that sees business as an integral part of society rather than an institution separate and purely economic in nature (Freeman et al., 2005). In contrast to what is commonly believed, in the early history of modern industrial organisations, profit maximisation was not the absolute law of business; instead, organisations were expected to exist for the public good (Kochan et al., 2000).

The concept of stakeholder is not easily defined; it ranges from consideration of all people with an interest in the organisation as stakeholders to a more narrow view of those who have a specific contract binding them to that organisation. Donaldson et al. (1995), presenting the former view, define stakeholders as persons or groups that basically have an interest in some aspect of corporate activity. Therefore, they identify stakeholders by their interests in the corporation, regardless of whether the corporation has any interest in them. They further state that 
the stakeholders' interests should be of intrinsic value, meaning that each group should be considered for their own sake and not to further the interest of other groups, such as shareowners. Post et al. (2002), presenting the latter perspective, define the stakeholders in a corporation as "the individuals and constituencies that contribute, either voluntarily or involuntarily, to its wealth-creating capacity and activities, and that are therefore its potential beneficiaries and/or risk bearers" (p.19). In this definition, the term stakeholder implies people who have a stake in the organisation, i.e., something to gain or lose. Hatch et al. (2003) further exemplify stakeholders not only as employees, customers, investors, suppliers, partners and regulators but also as people with special interests and local communities. Post et al. (2002) additionally include unions, supply chain associates, governments and alliances besides the former interest groups. Whereas, for example, employees are linked to the organisation through internal contracts, other external interests may be unaware of their implicit relationship with the corporation until something draws attention. Post et al. (2002) narrow the term stakeholder down to individuals who either have a stake in the firm - i.e., something to win or lose - or have certain power over the organisation or contribute valuable resources that are critical to the firm's success and that they may risk by their commitment. According to this definition, stakeholders are identified as people with a common interest in that the organisation is operated in such a way that it adds some kind of value for them. Kochan et al. (2000) see the reason for stakeholder involvement as being a search for "a better balance in the distribution of economic and social benefits and risks" (p.369).

In the present study, there is no organisation that can define its stakeholder; instead, we in this project have defined stakeholders as an entire industrial sector: the Swedish manufacturing industry. Prieto-Carron et al. (2006) argue for a critical research agenda establishing a genuine human-centred approach to stakeholders. They further stress a need for approaches based on participatory and collaborative methodologies, for investigating power structures both within organisations and within society. Hence, we have explored new approaches to an entire business sector's organisational development in this study, by including both internal and external stakeholders in workshop dialogues. We have defined the manufacturing sector's stakeholders as employees, managers, trade unions and industry associations. In addition to these stakeholder groups, we have specifically invited young people as future employees, managers or shareholders, and also as current stakeholders whose perceptions, ideas, thoughts and visions about the future of industrial work needs to be heard.

\subsection{Corporate Social Responsibility}

The concept of corporate social responsibility (CSR) has a focus on involvement of stakeholders in corporate activities. CSR has been described as the buzzword of the millennium (Pedersen, 2006) because an increasing number of both scholars and practitioners are adopting a variety of approaches to the concept. CSR is defined as a concept concerning companies' incorporation of social and environmental considerations into their business operations, strategies and interactions with stakeholders (Commission of the European Communities, 2006). Thus, the concept of CSR implicates seeing the company as integrated with, rather than isolated from, society and the environment (Pedersen, 2006). But even if stakeholders' requests for social responsibility of organizations has dramatically increased over the past decade (Brønn et al., 2003), in our view, the Swedish industrial sector has not adjusted its operations accordingly by inviting a diversity of stakeholders into discussions of strategies, workplace design and work tasks.

Carroll (1999) refers to early writings on the subject as, e.g., Bowen's Social Responsibility of the Businessman in 1953 and McGuire's Business and Society in 1963. Both of these writings include, e.g., business' obligations to take interest in politics, the welfare of the community, education, developing 'good' workplaces and socially desirable lines of action, besides their economic and legal obligations (Carroll, 1999). In Europe, laws regulate some aspects of corporate social responsibilities. In 2004, the International Institute for Sustainable Development defined a proposition for an ISO standard concerning the concept of CSR as an organization's contribution to a balanced promotion of sustainable development in economic growth, social development and environmental protection (IISD, 2004).

The concept is also said to include activities ranging from purely altruistic, one-off events to long-term efforts addressing stakeholder expectations, ethical obligations, legal requirements and universal principles (IISD, 2004). The proposed standard definition, as set forth by IISD, does not make the picture of CSR any clearer. The difficulty in defining the concept is also recognized by Brønn et al. (2001), who assert that knowledge of CSR is diverse and often vague and that in both countries and companies people are uncertain of its relevance or application. Also, some CSR guidelines in policies expect a 'respect' for laws and regulations, for socio-cultural values, such as gender and minority relationships, for the role of the family and for an active commitment in cultural and political life (Brønn et al. 2001). Although recognizing the potential of such guidelines, we consider them to be too general and too vague to really have impact on business. There are no explanations in policy 
regulations addressing the meaning of the often used CSR words 'respect' or 'ethics', what those words means in a company's day-to-day business and interactions with stakeholders. Likewise, there are no comprehensive analyses of why CSR is important for both society and corporations, who should be involved and how CSR activities should be managed. Post et al. (2002) assert that companies do not deserve to be in business if they do not act in accordance with the dominating norms, rules and values of a society. Despite agreeing that there is a need for some companies' socio-cultural adaption, we mean that, within CSR, there is an additional need for questioning the existing norms and practices. In accordance, Prieto-Carron et al. (2006) claim there is a need for a critical perspective on organizations' recognition of the roles of power, class and gender. Further contributing to the former argument is the claim that organizations are not being able to define their social responsibility on their own; therefore, some emphasize having active dialogues with other parts of society (IISD, 2004).

However, if carefully implemented and managed, we do believe that there is great potential within the concept of CSR. The recent stakeholder interest in the concept is, for example, said to be concerned with the environmental movement, sustainable development and organizational learning (Brønn et al., 2003). There are, however, arguments for various stakeholders having diverse views of these issues compared with corporations. Hence, some stress the need for understanding and undertaking multiple stakeholder relationships when dealing with business strategies and future visions (Brønn et al., 2003; Miles et al., 2006). Research studies in pro-active corporate social responsibility have, for example, been addressing corporations taking on responsibility for overproduction of goods and the consequent environmental impact (Manzini et al., 1992) or designing environmentally friendly products that also appeal to customers (Manzini et al., 1992; Shrivastava, 1995). Undertaking CSR activities is said to enhance brand reputation and image (Leonard et al., 2003). In short, engaging stakeholders in CSR activities is recognised as good business.

\section{The Study}

In the area of design, a human-centred perspective includes understanding the context, such as system's functions and structures, what stakeholders need, which preferences they have and what kind of interactions they are involved in (Holzblatt et al., 1993; Beyer et al., 1997). In the late 1960s, Participatory Design (PD) originated in worker collaborations in the design of workplaces and tasks (The Design Council, 2006). In Scandinavia, PD has a long tradition, as expressed in the Utopia project in the 1980s (e.g., Ehn, 1988; Bødker et al., 2000). Participatory Design means that the people who will use the resulting space participate in the design process, which opens up entirely new forms of cooperation and collaboration. Drawing inspiration from PD and stakeholder theory, we in this study propose scenario-based workshop dialogues as activities that can link various external and internal stakeholders together and create relationships that explore meaning, production and values both within and outside of an organisation. Communication is one way to develop, organise and disseminate knowledge (Duncan et al., 1998). A design approach includes investigating "how it ought to be" (Simon, 1996), in this case meaning ideas and visions of what the manufacturing sector ideally would be like.

In this study, the participants were 23 students in an upper secondary class, including 10 young men and 13 young women aged 17-18 years. The local context for these young people is the northern part of Sweden, in a city in which the major employer is a large process industry. Notably, the young people's impression of the manufacturing sector may be influenced by this industry. The participants were initially introduced to the project idea and our intention of using their future scenarios as means for dialogues with other project interest groups. All agreed to participate and agreed to our use of their scenarios. The workshop began with an open-ended discussion, inspired by the focus group methodology described as useful for creating interactive communication among a group of people (Kitzinger, 1994). A focus group approach is furthermore said to be useful for investigating values of a phenomenon (Ståhlbröst et al., 2006), in this case the young people's perception of the manufacturing sector and their visions of future work.

First, the participants were asked to individually select an image that in one way or another represented "the future' for them. The images used during this event were both intangible visualisations, such as a sky or a beach, and images of tangible objects and environments, such as artefacts, people, technologies and contemporary production environments, drawing on the idea of stimulating their individual reflections of the future (Rehal et al., 2006). Thereafter, in groups of 3-4 people, the students were asked to discuss the meaning of the images. They were further encouraged to discuss characteristics of 'good' jobs, colleagues, tasks and premises as well as their perceptions of the manufacturing sector. The images themselves are not directly significant, based on the presumption that the images act as mediums for personal reflections of the subject discussed. After the discussions, the participants were asked to write an individual future scenario describing them working in a future factory. Carroll (1997) defines a scenario as a description of a meaningful episode. He further asserts that in design, scenarios can evaluate meaning through claims analysis, wherein positive and negative outcomes can 
be considered through 'what if'-questions. Furthermore, Carroll (2000) sees scenarios as a tool to promote work-oriented communication among stakeholders, helping to make design activities more accessible to a variety of people who thereby have the opportunity to participate in the process.

The objective of the current study was to understand these young people's future visions of work and their perceptions of the present manufacturing sector. This objective guided the analysis of the discussions, image choices and scenario writings inasmuch as our intention was to identify both coherence and disagreement in the young people's expressions. From such an analysis, needs and preferences can be drawn for specific purposes. There is also a presumption that the preferences of a particular target group can provide value beyond that of any singular development process and that needs last longer than any solution (Patniak et al., 1999). In the analysis, we were able to draw conclusions based on individual analysis and emerging vertical patterns in the material. Individual horizontal analysis is said to identify both implicit and explicit statements and vertical analysis is said to assist in clustering statements into higher-level categories and themes through identification of common and shared statements (Thomsson, 2010).

The purpose of this study has not been to use the young people's statements as representative of general attitudes and opinions among all adolescents. In contrast, our intention has been to use the scenarios as inputs and stimuli for discussion. Thus, in workshop activities with other stakeholder groups, we have discussed the scenarios' implications for the Swedish manufacturing sector.

\section{Findings}

As mentioned above, in the analysis of the material, we strived for identification of individual values and preferences as well as overall themes among all scenarios regarding future work and workplaces. The individual preferences among this group of young people consist of values such as making good money, having flexible working hours, being able to travel and having creative and challenging work tasks. Several of the individual values in this study have also been described in previous studies that have not focused on young people in particular (e.g., Judge et al., 1997; Lievens et al., 2003; Highhouse et al., 2003; Lievens et al., 2007; King et al., $2005 ; 2008)$. These individual values and preferences expressed by the young people will serve as the basis for proposed criteria for future industrial workers in the Future Factory project.

In addition, the overall themes in the scenarios illustrate some interesting trends. The young generation of today is said to be facing a substantially different situation than previous ones due to the many different life choices that today's young people face (Gillberg, 2010). According to this view, life choices impact how individuals see themselves. For example, the increased amount of information from media and internet, the increased space for taking action, the liberation from local contexts and the understanding of the possibility of doing things in completely different ways are all aspects that are said to influence and have consequences for today's youths (Ziebertz et al., 2005; Lindgren et al., 2005, Gillberg, 2010). In the scenarios, the overall themes consist of an ambition to make a difference, 'do good' and expresses great environmental awareness. In several of the scenarios, the young people accentuate a value of both individual and corporate social responsibility. For example, some of the young people in the scenarios emphasised "doing something that benefits all humans" as well as company-specific environmental aspects, such as products being sustainable, ecological and recyclable, technologies being environmental friendly, energy being provided by own production and premises being "in harmony with nature". Several of the young people stressed transformation of thinking and acting regarding production. Most of the young people seemed optimistic towards the prospect of being able to do so; however, not all shared this view. In the following text, we have translated some quotes we found to be significant and given them aliases in order to depersonalise them. The preference for "making a difference" and "doing good" is illustrated in the following quote from one of the scenarios:

"To work within industry must be a 'good' job, something that people all around the world benefit from. The workplace should be well designed, as a work environment should be, not as they are in factories. Every employee cares for the environment and society as much as I do. I would like to be a person that comes up with solutions for a better future for all humans, including solutions for better working environments." (Anna, 18)

However, as already mentioned, some of the young people expressed a cynical, alienated, pessimistic, disillusioned perspective, which Eckersley (1999) refers to as a transformational attitude. The following quote is indicative of this:

"It feels as if the factories of today are destroying the Earth, polluting it, because we humans always want more and therefore are getting lazier and fatter. For me, it reflects human's selfishness." (Karl, 18)

In the expressions of disillusioned and pessimistic perspectives, as illustrated above, values are not clearly 
elucidated. Still, we consider them to be illustrations of some of the aforementioned requests for transformation of ways of thinking regarding production and social responsibility. They express an aversion towards factory work and all things associated with it, which these young people express as, for example monotonous repetitive tasks, hierarchies, pollutions and the "ever increasing production of worthless products".

To further illustrate the discrepancy in the young people's visions of a future factory, we present two scenarios: utopia and dystopia, originating from the young people's scenarios. These scenarios could be described as ideal types (Weber, 1983) that highlight certain purified features of phenomena expressed by the young people. An ideal type can be a tool to describe and explain functions and characteristics of certain social phenomena (Weber, 1983). By presenting these scenarios, we believe that they can assist in a better understanding of these young people's visions of the future as well as stimulate critical reflection on the manufacturing sector. Parrish (2006) also recognises scenario narratives as means for shared values among groups of people. Therefore, our method has been to share both the young people's visions and their concerns with other project stakeholder groups, with the scenarios thus becoming a tool for dialogue. The following two scenarios are the result of our analysis, meaning that although the young participants in the activity have not written them, all the input information comes from their scenarios. However, we believe these scenarios, accompanied by some images of the young people's choices (see figures 1-4), serve a useful role both in presenting the discrepancies in the young people's visions and in presenting the communicative tool of scenarios.

\subsection{Utopia scenario}

The Future Factory is situated in a big city, although there are a lot of parks and green areas in the vicinity. The location ensures easy access to work and is in a community with day-care centers, schools and shops nearby. The Future Factory has clean, bright and airy working environments. The premises have nice interiors with 'modern designs' and the factory itself has a 'modern architecture' that blends into the city. All facilities are situated close to each other, contributing to a transparent and flat organization. An important aspect in the Future Factory is the social responsibility taken on by the company and all employees. This includes environmental concerns being considered in every aspect of work and production and the company financing projects to assist the third world, for example.

The main part of work is done above ground, but some automated production is situated below ground and performed in office-like environments. The work includes creative tasks, with workers continuously learning and participating in innovative production system development. Working in the Future Factory includes travelling opportunities and collaborating with a diversity of people from all over the world. All employees participate in product and production development. As a co-worker in the future factory, you have access to several sports and relaxation facilities. It is a challenging but not physically demanding job; technology does the heavy work without replacing the humans. Work colleagues in the Future Factory are committed to do a good job, prefer working in teams and have the social skills to do so. Women and men, of course, work on equal terms. All employees feel important and needed and there are constant dialogues and participatory activities to ensure an open space with opportunities to influence the company, a good psychosocial climate and a search for prospective innovations. Working at the Future Factory is a respectable job for which each co-worker has been chosen with care and in which you make good money.

\section{Figure 1.}

Figure 2.

\subsection{Dystopia scenario}

The Future Factory is yet one more of the plants destroying the Earth. It is located in a designated area separate from human living zones, one in which no one cares about whether pollution and environmental toxins destroy nature. To be able to work here safely, you have to wear gas masks; however, no one does because the workers do not understand that the environment is dangerous and no one tells them.

This factory has these conditions because of humans' constant striving for short-term profits and the ever-increasing production of goods. In the past few decades, robots have replaced most of the human work force, although in recent years, humans have become cheaper than technology, resulting in the Future Factory now hiring personnel. The work involves monotonous and repetitive tasks in a assembly line, resulting in work-related ill health for most employees. Some job tasks consist of boring operating tasks, running the out-dated automated production machines that still work. The working environment is dirty, and there is no way to see outside when you are in the plant. Still, most workers are happy to do the job, because finding a job is not easy these days, even though the pay is not enough to feed a family. 
Employees do not understand what they are doing or why they are doing the tasks; nobody tells them anything. They have never seen, or let alone spoken to, managers, whom the workers refer to as the 'the invisible force'.

Figure 3.

Figure 4.

\subsection{Dialogues}

With inspiration from Schön (1995), the next step meant reflecting on the scenarios in workshops with people working within the manufacturing sector. In a series of workshops, 18 female production engineers, systems designers, human resource managers, CEOs, industrial designers, architects, students and researchers from 11 companies participated in the design of a conceptual future factory. In the first of these workshops, the Utopia and Dystopia scenarios were introduced as well as both the individual and overall visions and concerns that the young people expressed during the workshop. In the succeeding workshops, the scenarios were used for critical reflections on current systems, change processes and future solutions. Beforehand, we considered that the scenarios expressed idealized positive and negative visions, illustrating both visions and concerns held by these young people. The participants, however, experienced the utopian scenario as not idealistic, but rather a description of current practice or practice in upcoming years. The following quotation from one of the participants is indicative of this:

"This is just like a description of our corporation! This is certainly not utopian; this is how we work today. Then, perhaps we can't be in the middle of a big city, however we work actively with parks and green spaces, because it's nice and because it picks up dust and makes a better working environment. We try to make our premises attractive and nice, but it's not easy with an old plant. We would like to have this transparency between different activities, but as I said, we have the buildings and premises we have. However, we try to find tools for better communication and cooperation."

This quotation can be seen as an expression of people within the manufacturing sector having a different image and perception of manufacturing work compared with people outside the industrial sector. This is reminiscent of the aforementioned description of a 'future gap' as the discrepancy between perceptions and images held by internal and external stakeholders (Miles et al., 2006). One explanation is that the current industrial sector actually has a similarity with the utopian scenario, meaning that external stakeholders have little awareness and understanding of contemporary manufacturing. Another explanation can be that 'insiders' do not compare themselves with other sectors, as, e.g., young people do, and that this proposed new and transformed industrial sector has not been communicated to people outside the sector. Whatever the explanation is, this reveals a need to communicate with stakeholders to a greater extent. When the participants were asked to reflect on actions and activities, to communicate strategies and visions and to gain stakeholders' views and interests, one participant said the following:

"Social engagement and social responsibility is very important now, we make a sustainability report every year that includes how we work with various activities such as ethical issues, environmental issues and so on. And of course we work in teams and try to cooperate between various divisions, it is important to involve different skills in dialogues. One of our employees recently said that he felt really involved in the business and finally understood the challenges. It is not possible today to just decide something and then tell people to do it, you need to think and learn about why the change is needed. All companies work in this direction, it is not utopian - it is what we do today."

This quotation illustrates an increased awareness of dialogues with internal stakeholders as important, although as other participants have reflected as well, it indicates little or no collaboration with external stakeholders.

Based on our understanding, the participants have an awareness of the need for greater communication of the industrial sector's business and activities, although none of them have so far worked with a diversity of stakeholders on these issues. One conclusion from the study is, therefore, that although the participants did not think that the scenarios provided innovative ideas about practice, the scenarios did provide an understanding of the need for communication among multiple stakeholders. In several of the workshops, the participants discussed the scenarios in a very lively manner; hence, we believe the scenarios have provided some kind of lasting impression. The dystopian scenario turned out to be a provocation that initially made the participants defend the industrial sector in general and their own businesses in particular. After some reflection, they agreed that there could be such a perception of the sector in society and perhaps even more so among young people. According to these participants, the industrial sector does not communicate the business properly, and as a consequence, many people neither know what a contemporary factory looks like nor how it operates. The following quote indicates 
one participant's first impression of the dystopia scenario;

"Wow, that was really bleak! However, I can't see this coming. People demand more today, not just work for eight hours or so, they want fulfillment and challenges as well. We have to consider how to become more attractive employers."

In the dialogues, the participants talked about various stakeholder activities that could contribute to becoming more attractive employers and to making production more effective and sustainable, as illustrated in the following quotation:

"I work with environmental issues, and Dystopia deals with issues I deal with every day. This is something we are very much aware of today, both in our company and in the society. We try to work pro-actively with education of all employees so they understand their role in this. Then about producing more and more goods, well that is the reality we have. But the challenge is it to make these things work together, I mean, if we make profit, we can invest more in social responsibility. There may not even be a contradiction in working with environmental awareness and produce more effectively: some investments pay off in decreased maintenance for example, you just have to be aware of it and work with it constantly in mind. For me, it's the future; you should consider the resources, the environment and the working environment continuously in order to become a more effective and attractive work place. It is important to recognize the connections between social responsibility and effective production, to see 'the big picture'."

We consider this quote to be indicative of an understanding of social responsibilities as important and as activities that may contribute to both social and economic interests. The scenarios helped illustrate various images and perceptions that exist of the industrial sector, and thus the scenarios contributed to a discussion of the need for multi-stakeholder dialogues. This awareness could be achieved by other means; however, we consider the scenarios to be an effective tool in communicating visions and concerns from stakeholder groups that the participants rarely involve in their companies. In sum, the scenarios proved to be a valuable tool for illustrating the future gap between internal and external stakeholders' perceptions of the sector.

\section{Discussion}

There is a saying stating that the best way to predict the future is to invent it (Kay, 1989). One way of looking at this study is to see it as a way of striving to predict the future by discussing multiple stakeholders' needs and preferences and consequently inventing a conceptual future factory based on this. Furthermore, the project's aim has been to create a vision of a good future factory design, with a production system, workplace premises, employee interactions and experiences that not only are functional but also are satisfying symbolic dimensions for multiple stakeholders. Within the field of design, this is a common approach to developing solutions to proclaimed problems. Our understanding of the industrial sector is that manufacturing companies in general have not had a need to promote themselves as employers of choice and thus have not seen a need to communicate with multiple stakeholders. The Commission of European Communities proclaims a need for companies to become involved in stakeholder activities because it "matters to our children and future generations who expect to live in a world that respect people and nature" (Commission of the European Communities, 2006 p. 10). Based on these claims, and on Donaldson and Preston's aforementioned emphasis on stakeholder relationships for their own sake, we believe there is a need for multiple stakeholder activities within the industrial sector.

Furthermore, we propose that most companies should consider young people as an interest group. They can, we argue, provide a different perspective on aspects of corporate activity. For example, young people who express negative attitudes towards industrial work can be seen as stakeholders insofar as they are prospective employees, customers or investors, or simply as part of a wider society with which the companies should interact for democratic reasons. We think that the future of the industrial sector is in need of a transformation of how the sector reacts to and interact with a diversity of stakeholders. According to Wells (1998), in order for firms to be competitive in the future they need to engage with the complexities of the environment in new and innovative ways. Additionally, Freeman (1984) proposes that positive financial outcomes will result from engaging with stakeholders, in addition to emphasizing the need for stakeholder participation for its own sake. However, according to Pedersen (2006), positive financial outcomes from stakeholder activities are difficult to measure in traditional ways because there cannot be a clear-cut distinction between social and economic interests, as economic decisions have social consequences and vice versa.

As mentioned above, the aim of this paper has been to explore future scenarios as a means for multi-stakeholder dialogues. Therefore, we have strived to illustrate scenarios as a tool for communicating various stakeholders' needs and preferences as well as to use the scenarios for critical reflections on strategies and visions with multiple stakeholders. Employing a design approach for us means placing humans at the heart of solutions, 
thereby including various stakeholders as experts on their own needs and preferences.

Within the field of design, it is recognized that problems can only be analyzed by being solved (Carroll, 2000), meaning that it is the exploration of context and situations that creates understanding that leads to satisfying solutions. Good design goes beyond problem solving; as mentioned above, it creates systems, spaces, interactions and experiences that also satisfy symbolic dimensions for stakeholders.

The Future Factory project idea originated from the difficulty in recruiting women and young people to the Swedish manufacturing sector. Therefore, a proactive approach of including those stakeholder groups in explorations of the future was used in the project. The idea is that a thorough exploration with multiple stakeholders would better secure a good project outcome. Despite the design approach of this project, the problem is not yet solved; we do not present a general solution for how to attract more women or young people. Rather, in this paper, we aimed to promote critical reflections on the implications of a business sector doing things the 'traditional way', meaning not including multi-stakeholders in dialogues about future strategies and visions. Conversely, in this paper, the use of scenarios as a tool for multi-stakeholder dialogues has been explored.

The study included discussions and scenario writings due to the consideration that these would provide us with richer information than material gained from surveys or interviews. Despite this being a study that does not aim to generalize findings to all young people's values for future work and workplaces, we consider the scenario-based design to be a useful tool for communicating visions and concerns held by some stakeholders. Therefore, one conclusion is that the use of scenarios resulted in rich material of visions and concerns of the future held by these young people. In addition, the use of scenarios for critical reflections assisted in illustrating a gap between perceptions and images held by people working within the sector and these young people. We believe that this 'future gap' needs to be addressed with better communication than is currently employed in practice and with a more pro-active participatory dialogue with multiple stakeholders concerning future activities. Negative attitudes towards a sector represent a negative image and reputation of the business, and there is a concern among our participants about implications, such as a decrease in products and services or difficulty in recruiting personnel. So far, the manufacturing sector has had a good supply of labor and therefore has not been forced to take the symbolic dimensions of work and workplaces into account. All the same, the current interest in stakeholder relationships is said to point towards pressure on contemporary organizations to focus attention on the symbolic dimensions of their activities (Kärreman et al., 2008). As Hatch and Schultz (2003) state, the importance lies not only in positioning the company in the market but also in creating continuous development of organizational structure, physical design of premises and a workplace culture that supports the generation of meaning in the corporation.

In our view, taking on multiple stakeholder activities has the potential to be an effective approach for organizational development and change management. Dialogues with a diversity of both internal and external stakeholders can assist in communicating that the sector is an employer of choice and possibly contribute to securing future production. This is something we consider critical to the Swedish industrial sector. To do so, however, requires a shift from a focus on rationality and standardization towards exploration of multiple stakeholders' values and visions of work and workplaces.

We recognize that there are other perspectives that need to be addressed within stakeholder activities. For example, Prieto-Carron et al. (2006) suggest a perspective of power and class in addition to a focus on the Third World. In this study, however, we have focused on young people in relation to the Swedish manufacturing industry. The aim has been to explore means to address a multiple stakeholder perspective that can be used to address a variety of visions and concerns. In this, scenarios have shown great promise as useful tools for sharing stakeholder values, facilitating dialogues that have illustrated the possibility of increasing awareness of various perspectives and aspects. As Carroll $(1997 ; 2000)$ states, maintaining a continuous focus on situations and their consequences for human work and activity promotes learning about the structure and dynamic of a problem domain, seeing situations from different perspectives and managing trade-offs to reach usable and effective outcomes. Kochan et al. (2000) claim the notion that corporate downsizing and outsourcing, stagnant wages, increased inequalities, and declining union representation among other things may have broken the value relationship for some of the industrial sector's stakeholders. They further assert that, in bringing together multiple interests, stakeholders of firms have the possibility of being managed effectively when facing future challenges. Additionally, Wells (1998) proposes that the way people think dictates what they see and hence the future for which they can conceive of a strategy. Our interpretation of this is that a multi-stakeholder relationship may contribute to a broadened perspective on the future and what strategies to undertake. Wells also proposes that the only limit to the possibilities of a company is the minds of its people and what they are able to originate; 
hence, we think that multiple perspectives would provide greater possibilities.

Therefore, we propose that the industrial sector be pro-active and use, scenarios as means for multiple stakeholder dialogues. In our view, this has the possibility of contributing to, e.g., a higher level of inclusion, life-long learning and employability, better innovation performance, a more positive image of the industrial sector, environmental protection and a fundamentally more sustainable future. Our proposal includes critical reflection on current concepts and practices through scenarios and active engagement with stakeholders. If today's young people express negative opinions about the manufacturing sector, we consider it high time for a transformation of the ways in which organizations involve and connect to stakeholders; it is time to take action to minimize the future gap.

\section{References}

Beyer, H., \& Holzblatt, K. (1997). Contextual Design: Defining Customer-Centered Systems. San Francisco: Morgan Kaufmann Publishers Inc.

Bødker, S., Ehn, P., Sjögren, D., \& Sundblad, Y. (2000). Co-operative Design - perspectives on 20 years with the Scandinavian IT Design Model. KTH/Royal Institute of Technology: Stockholm.

Brønn, P. S., \& Brønn, C. (2003). A Reflective Stakeholder Approach: Co-orientation as a Basis for Communication and Learning. Journal of Communication Management, 7 (4), 291-303. doi:10.1108/13632540310807430, http://dx.doi.org/10.1108/13632540310807430

Brønn, P. S., \& Vrioni, A. B. (2001). Corporate social responsibility and cause-related marketing: an overview. International Journal of Marketing, 20, 207-222.

Carroll, A. B. (1999). Corporate Social Responsibility: Evolution of a Definitional Construct. Business \& Society, 38 (3), 268-295. doi:10.1177/000765039903800303, http://dx.doi.org/10.1177/000765039903800303

Carroll, J. M. (1997). "Scenario-Based Design”. In M. Helander, T.K. Landauer \& P. Prabhu's (Eds) Handbook of Human-Computer Interaction, pp. 383-404. Amsterdam: Elsevier Science.

Carroll, J. M. (2000). Five reasons for scenario-based design. Interacting with Computers, 13, 43-60. doi:10.1016/S0953-5438(00)00023-0, http://dx.doi.org/10.1016/S0953-5438(00)00023-0

Commission of the European Communities (2006). Implementing the Partnership for Growth and Jobs: Making Europe a Pole of Excellence on Corporate Social Responsibility. Brussels: Commission of the European Communities. [Online]

http://eur-lex.europa.eu/LexUriServ/LexUriServ.do?uri=COM:2006:0136:FIN:en:PDF (July 5, 2011).

Donaldson, T., \& Preston, L. E. (1995). The Stakeholder Theory of the Corporation: Concepts, Evidence, and Implications. The Academy of Management Review, 20 (1), 65-91. [Online] Available: http://www.jstor.org/stable/258887 (July 5, 2011).

Duncan, T., \& Moriarty, S. E. (1998). A Communication-Based Marketing Model for Managing Relationships. The Journal of Marketing, 62 (2), 1-13, [Online] Available: http://www.jstor.org/stable/1252157 (July 5, 2011).

Eckersley, R. (1999). Dreams and expectations: young people's expected and preferred futures and their significance for education. Futures, 31, 73-90. doi:10.1016/S0016-3287(98)00111-6, http://dx.doi.org/10.1016/S0016-3287(98)00111-6

Ehn, P. (1988). Work-oriented Design of Computer Artifacts. Stockholm: Arbetslivscentrum.

Freeman (1984). Strategic management: a stakeholder approach. Boston, Mass.: Pitman.

Freeman, E., \& Liedtka, J, (2005). "Stakeholder Capitalism and the Value Chain". In A. Bettley, D. Mayle \& T. Tantoush (Eds) Operations management: a strategic approach. (pp. 35- 47). London: Sage.

Gillberg, G. (2010). Individualiseringens villkor. Unga vuxnas föreställningar om arbete och självförverkligande. Doctoral thesis. Gothenburg: Gothenburg's University. [Online] Available: http://gupea.ub.gu.se/handle/2077/21996 (July 5, 2011).

Hatch, M. J., \& Schultz, M. (2003). Bringing the corporation into corporate branding. European Journal of Marketing, $\quad 37 \quad$ (7-8), $\quad 1041-1064 . \quad$ doi:10.1108/03090560310477654, http://dx.doi.org/10.1108/03090560310477654

Highhouse, S., Lievens, F., \& Sinar, E. F. (2003). Measuring Attraction to Organizations. Educational and Psychological Measurement, 63, 986-1001. doi:10.1177/0013164403258403, http://dx.doi.org/10.1177/0013164403258403 
Holzblatt, K., \& Beyer, H. (1993). Making Customer-centered Design Work for Teams. Communication of the ACM, 36 (10). doi:10.1145/163430.164050, http://dx.doi.org/10.1145/163430.164050

IISD- International Institute for Sustainable Development. (2004). ISO Social Responsibility Standardization. An outline of the issues. Manitoba: International Institute for Sustainable Development. [Online] Available: http://www.iisd.org/pdf/2004/standards_iso_srs.pdf (December 8, 2010).

Isaksson, P. (2008). Leading companies in a global age- managing the Swedish way. Vinnova Report VR 2008:14. [Online] Available: http://www.vinnova.se/upload/EPiStorePDF/vr-08-14.pdf (February 25, 2011).

Judge, T. A., \& Cable, D. M. (1997). Applicant Personality, Organizational Culture, and Organization Attraction. Personnel Psychology, 50, 359-393. doi:10.1111/j.1744-6570.1997.tb00912.x, http://dx.doi.org/10.1111/j.1744-6570.1997.tb00912.x

Kärreman, D., \& Rylander, A. (2008). Managing Meaning through Branding - the Case of a Consulting Firm. Organization Studies, 29 (1), 103-125. doi:10.1177/0170840607084573, http://dx.doi.org/10.1177/0170840607084573

Kay, A. C. (1989). Predicting the Future. Stanford Engineering, 1 (1), 1-6. [Online] Available: http://www.ecotopia.com/webpress/futures.htm (July 5, 2011).

King, C., \& Grace, D. (2005). Exploring the role of employees in the delivery of the brand: a case study approach. Qualitative Market Research, 8 (3), 277-295. doi:10.1108/13522750510603343, http://dx.doi.org/10.1108/13522750510603343

King, C., \& Grace, D. (2008). Internal Branding: Exploring the employee's perspective. Brand Management, Vol. 15, No. 3, pp. 358-372. doi:10.1057/palgrave.bm.2007.48, http://dx.doi.org/10.1057/palgrave.bm.2007.48

Kitzinger, J. (1994). The methodology of Focus Groups: the importance of interaction between research participants. Sociology of Health \& Illness, 16 (1), 103-121. doi:10.1111/1467-9566.ep11347023, http://dx.doi.org/10.1111/1467-9566.ep11347023

Kochan, T. A., \& Rubenstein, S. A. (2000). Toward a Stakeholder Theory of the Firm: The Saturn Partnership. Organization Science, 11 (4), 367-386. [Online] Available: http://www.jstor.org/stable/2640410 (July 5, 2011).

Leonard, D., \& McAdam, R. (2003). Corporate Social Responsibility. Quality Progress, 36 (19), 27-32. doi:10.1108/14720700310497104, http://dx.doi.org/10.1108/14720700310497104

Lievens, F., \& Highhouse, S. (2003). The Relation of Instrumental and Symbolic Attributes to a Company's Attractiveness as an Employer. Personnel Psychology, 56, 75-101. doi:10.1111/j.1744-6570.2003.tb00144.x, http://dx.doi.org/10.1111/j.1744-6570.2003.tb00144.x

Lievens, F., Van Hoye, G., \& Anseel, F. (2007). Organizational Identity and Employer Image: Towards a Unifying Framework. British Journal of Management, 18, 45-59. doi:10.111/j.1467-8551.2007.00525.x, http://dx.doi.org/10.111/j.1467-8551.2007.00525.x

Lindgren, M., Lüthi, B., \& Fürth, T. (2005). The MeWe Generation-what business and politics must know about the next generation. Stockholm: Bookhouse Publishing.

Manzini, E., \& Cullars, J. (1992). Prometheus of the Everyday: The Ecology of the Artificial and the Designer's Responsibility. Design Issues, 9 (1), 5-20. [Online] Available: http://www.jstor.org/stable/1511595 (July 5, 2011).

Miles, M. P., Munilla, L. S., \& Darroch, J. (2006). The Role of Strategic Conversations with Stakeholders in the Formation of Corporate Social Responsibility Strategy. Journal of Business Ethics, 69, 195-205. doi:10.1007/s10551-006-9085-6, http://dx.doi.org/10.1007/s10551-006-9085-6

Parrish, P. (2006). Design as Storytelling. TechTrends, 50 (4), 72-82. doi:10.1007/s11528-006-0072-7, http://dx.doi.org/10.1007/s11528-006-0072-7

Patniak, D., \& Becker, R. (1999). Needfinding: The Why and How of Uncovering People's Needs. Design Management Journal, $10 \quad$ (2), 37-43. $\quad$ doi:10.1111/j.1948-7169.1999.tb00250.x, http://dx.doi.org/10.1111/j.1948-7169.1999.tb00250.x

Pedersen, E. R. (2006). Making Corporate Social Responsibility (CSR) Operable: How Companies Translate Stakeholder Dialogue into Practice. Business and Society Review, 111(2), 137-163. doi:10.1111/j.1467-8594.2006.00265.x, http://dx.doi.org/10.1111/j.1467-8594.2006.00265.x

Post, J. E., Preston, L. E., \& Sachs, S. (2002). Redefining the Corporation: Stakeholder Management and Organizational Wealth. Stanford: Stanford University Press. 
Prieto-Carron, M. Lund-Thomsen, P., Chan, A., Muro, A., \& Bhushan, C. (2006). Critical Perspectives on CSR and development: what we know, what we don't know, and what we need to know. International Affairs, 85 (5), 977-987. doi:10.1111/j.1468-2346.2006.00581.x, http://dx.doi.org/10.1111/j.1468-2346.2006.00581.x

Rehal, S., \& Birgersson, L. (2006). Associative Images as a Communication Tool to Improve the Dialogue between Designers and End-users. Paper to the conference Design Process and Human Factors Integration International Symposium, Nice 1-3 March 2006.

Schön, D. (1995). The Reflective Practitioner: How professionals think in action. Aldershot: Arena.

Shrivastava, P. (1995). The Role of Corporations in Achieving Ecological Sustainability. The Academy of Management Review, 20(4), 936-960. [Online] Available: http://www.jstor.org/stable/258961 (July 5, 2011).

Simon, H. A. (1996). The Sciences of the Artificial. (3rd ed.). Cambridge, Mass: MIT Press.

Ståhlbröst, A. \& Holst, M. (2006). Appreciating Needs for Innovative IT Design. International Journal of Knowledge, Culture and Change Management, 6 (4), 37-44.

The Design Council (2006). Red Paper 02. Transformation Design. London: The Design Council. [Online] Available: http://www.designcouncil.info/mt/RED/transformationdesign/TransformationDesignFinalDraft.pdf (July 5, 2011).

Thomsson, H. (2010). Reflexiva intervjuer. Lund: Studentlitteratur.

Weber, M. (1983). Ekonomi och samhälle: förståendesociologins grunder. Lund: Argos.

Wells, S. (1998). Choosing the future: the power of strategic thinking. Boston, Mass.: Butterworth-Heinemann.

Wikberg Nilsson, Å., Fältholm, Y., \& Abrahamsson, L. (2010). Reframing Practice through the use of Personas. Reflective $\quad$ Practice, 11(3), 285-298. doi:10.1080/14623943.2010.487376, http://dx.doi.org/10.1080/14623943.2010.487376

Ziebertz, H., \& Kay, W. (2005). Youth in Europe I: an international empirical study about life perspectives. Münster:LIT.

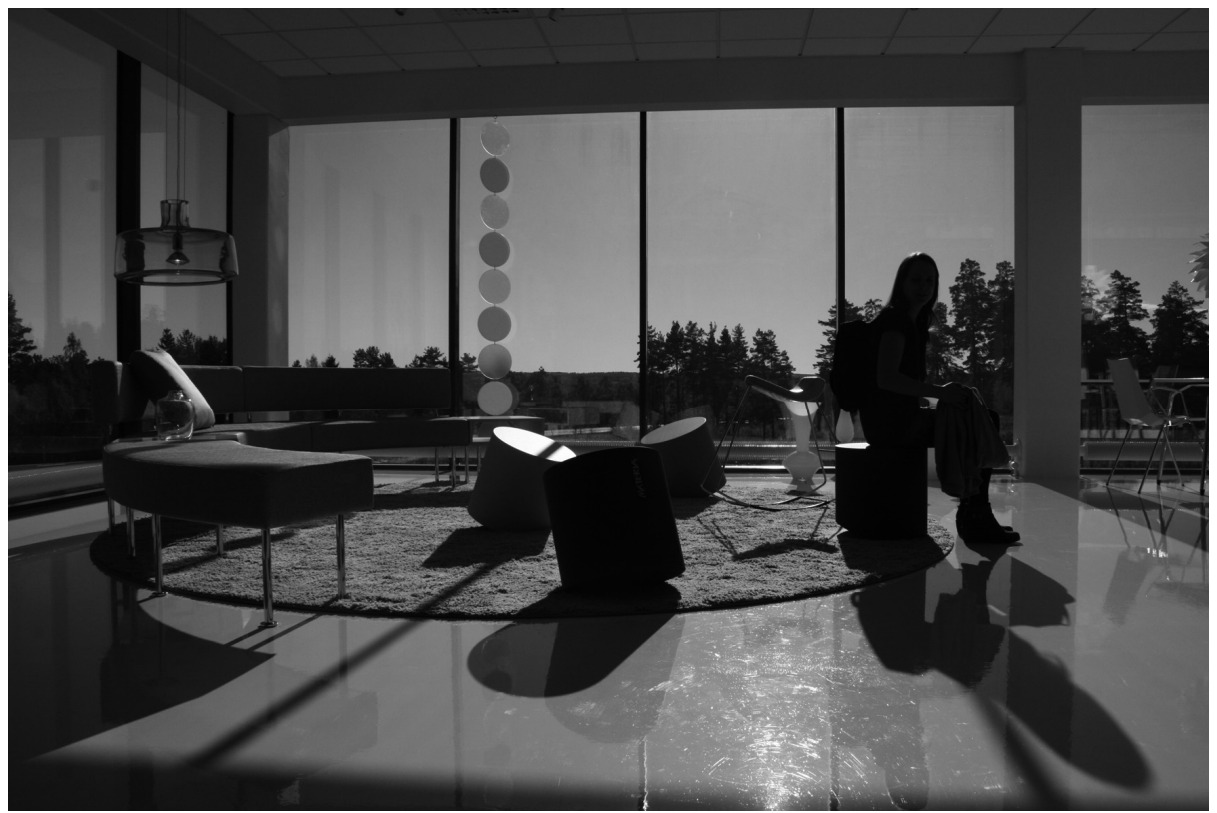

Figure 1. An illustration of some of the young people's preference for working environment (Photo: Author) 


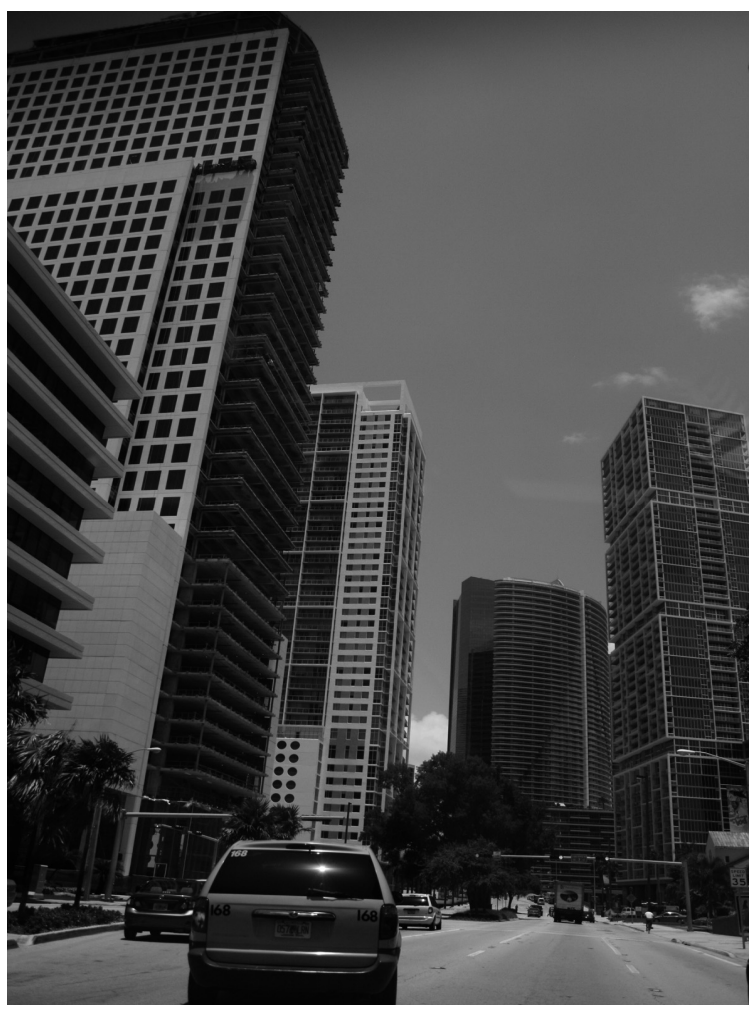

Figure 2. An illustration of the young people's preference for working in a big city (Photo: Author)

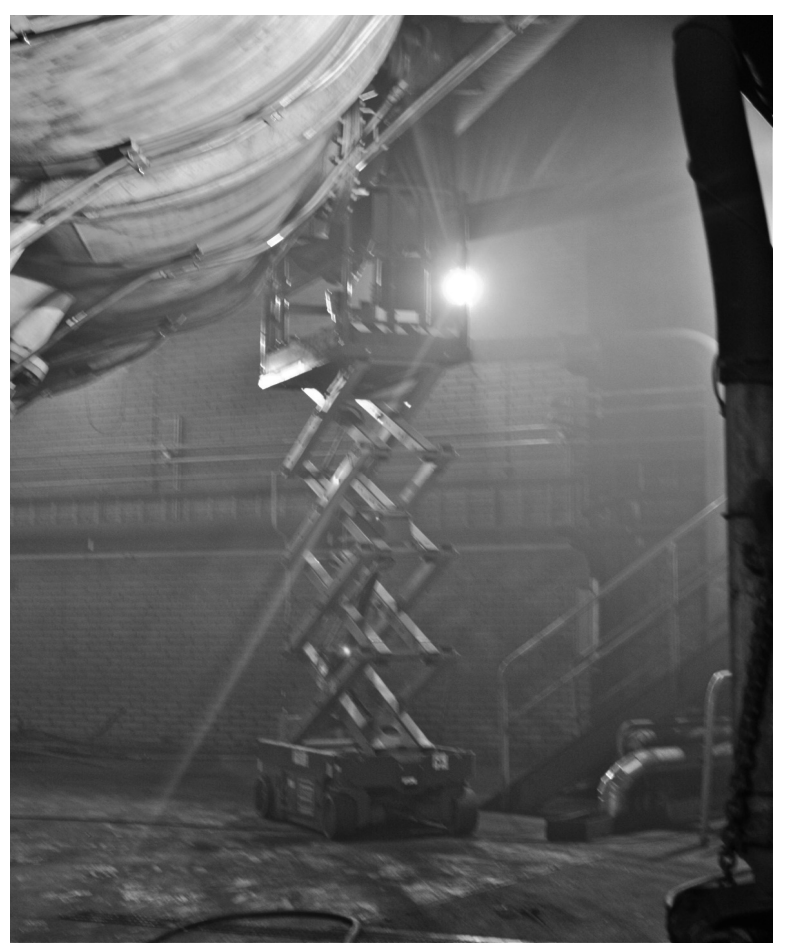

Figure 3. An illustration of a future vision of not being able to see outside (Photo: Author) 


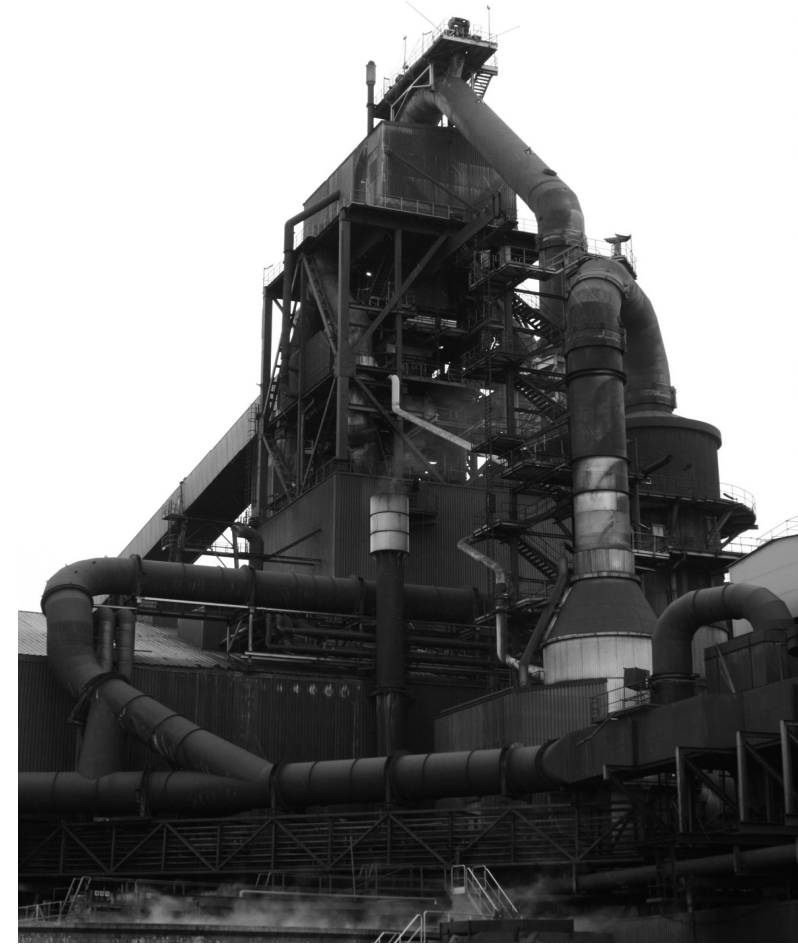

Figure 4. An illustration of a dystopian future perspective (Photo: Author) 